\title{
Characterisation of volatile compounds of pineapple peel wine
}

\author{
Li Zhang ${ }^{1,2}$, Chuang Zhou ${ }^{1,3}$, Yuan Yuan ${ }^{1,2}$, Xiao Gong ${ }^{1,2}$, Yuhao Hu ${ }^{1,2}$, and Jihua $\mathrm{Li}^{1,2,{ }^{*}}$ \\ ${ }^{1}$ Agricultural Products Processing Research Institute, Chinese Academy of Tropical Agricultural Sciences, Key Laboratory of Tropical \\ Crop Products Processing of Ministry of Agriculture and Rural Affairs, Zhanjiang 524001, P. R. China; \\ ${ }^{2}$ Hainan Key Laboratory of Storage \& processing of fruits and vegetables, Zhanjiang 524001, P. R. China; \\ ${ }^{3}$ Institute of South Subtropical Corp Research, Chinese Academy of Tropical Agricultural Sciences, Zhanjiang 524091, P. R. China
}

\begin{abstract}
An analytical program based on the headspace solid phase microextraction (HS-SPME) method combined with gas chromatography - mass spectrometry (GC-MS) was developed to extract and analysis profiling of volatiles from pineapple peel wine. In total, 57 volatile compounds were detected on the basis of the MS information and RI, including 25 esters, 9 alcohols, 8 acids, 7 phenolic compounds, 6 aldehydes and ketones, 1 terpene and 1 lactone, respectively. The types of esters are the most in various aroma substances, and the content of alcohols is the largest. Phenethyl alcohol, 3-methyl-1-butano, 2-methyl-1butano, 2,3-Butanediol and 2-Methoxy-4-vinylphenol were the major constituents.
\end{abstract}

\section{Introduction}

Pineapple(Ananas comosus L. [Merr.]), one of the most popular subtropical fruits, has plentiful nutrition and unique flavor. Pineapple is abundant in micronutrients and antioxidants, for instance, vitamin $\mathrm{C}$, polyphenols, flavonoids and phytochemicals ${ }^{[1]}$. In addition, it also contains sufficient amounts of minerals, especially potassium and calcium. Pineapple consumed in fresh and processed forms, widely processed into canned food, beverages, and food supplements. Simultaneously, a large number of peel, representing $29-40 \%(\mathrm{w} / \mathrm{w})$ of the whole pineapple weight, is discarded in processing industry ${ }^{[2]}$. However, abundant evidence proves pineapple peel contains crucial bioactive substance and aroma compounds ${ }^{[3-4]}$. The development of pineapple peel wine can not only help reduce waste, but also meet the strong public demand for novel quality products. Compare with the pulp, pineapple peel might contribute to the wine with more plentiful and unique flavors. Currently, little research on volatile compounds in pineapple peel wine is reported. Consequently, the purpose of this study was to investigate the characterisation of volatiles in pineapple peel wine to develop novel alcoholic beverage.

\section{Materials and Methods}

\subsection{Chemicals and reagents}

Yellow mauritius pineapple were obtained from Nanpai Farms (Zhanjiang, Guangdong Province) . Pectinase and cellulase were purchased from Shanghai Yuanye Biological Technology Co., Ltd.

\subsection{Wine making}

The pineapple peel was placed into fermentor containing distilled water at a ratio of $1.5: 1$ and then subjected to maceration treatment at $70^{\circ} \mathrm{C}$ for $30 \mathrm{~min}$. Afterwards, the mixture was cooled to $45 \pm 5^{\circ} \mathrm{C}$ and subjected to enzymatic hydrolysis, using pectinase and cellulase as catalysis. The must, adjusted the sugar content to $20^{\circ}$ Brix by sucrose solution, was fermented by Yeast QA23 on the concentration of $200 \mathrm{mg} / \mathrm{L}$ at $18^{\circ} \mathrm{C}$. Sodium metabisulfite was added up to a concentration of $60 \mathrm{mg} / \mathrm{L}$ to inhibit the growth of bacteria. Fermentation termination was determined when the sugar content remained keep stable.

\subsection{GC-MS analysis of the volatile compounds in the wine}

The sample was analyzed using HS-SPME-GCMS as previously reported, with modifications. $1 \mathrm{~mL}$ of wine sample was added into glass bottles containing $0.5 \mathrm{~g}$ of $\mathrm{NaCl}$. The fiber used for the extraction of the volatiles was the DVB/CAR/PDMS, and the procedure was carried out using the auto-sampler. The SPME fiber was extracted at $45^{\circ} \mathrm{C}$ for $15 \mathrm{~min}$ and then stabilized for 5 min. Subsequently, the fiber was inserted into the injection port of the GC device for thermal desorption. The thermal adsorption of the compounds in the fiber was fulfilled in a splitless manner at $250{ }^{\circ} \mathrm{C}$ for $5 \mathrm{~min}$. The analyses were via an GC-MS-QP2010 Plus, and a Rtx- $5 \mathrm{~ms}$ capillary column was used. The flow rate of the carrier gas was $1.08 \mathrm{~mL} / \mathrm{min}$. The temperatures of the interface and the ion ionization source were $250{ }^{\circ} \mathrm{Cand}$ $230{ }^{\circ} \mathrm{C}$, severally. The sequence of the $\mathrm{GC}$ oven program was as follows: $45^{\circ} \mathrm{C}$ for 2 minutes, at a rate of $5^{\circ} \mathrm{C} / \mathrm{min}$

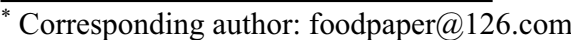


to $180^{\circ} \mathrm{C}$ for 27 minutes, and then at a rate of $20^{\circ} \mathrm{C} / \mathrm{min}$ to $240^{\circ} \mathrm{C}$. The ionization voltage was $70 \mathrm{eV}$, and data acquisition was carried out within a scan range of $\mathrm{m} / \mathrm{z} 35$ to 500. The identification of the volatiles was fulfilled using mass spectra and retention indices, and the area normalization method was used to quantitate ${ }^{[5]}$.

\section{Results and discussion}

\subsection{HS-SPME-GC-MS analysis of volatile compounds in wine sample}

HS-SPME-GC-MS was applied to detect volatile components of pineapple wine in this study. Fig. 1. showed the HS-SPME-GC-MS total ion current chromatograms of the sample. Results obtained showed that a total of 57 typical volatiles were detected on the basis of the MS information and RI, including 25 esters, 9 alcohols, 8 acids, 7 phenolic compounds, 6 aldehydes and ketones, 1 terpene and 1 lactone.

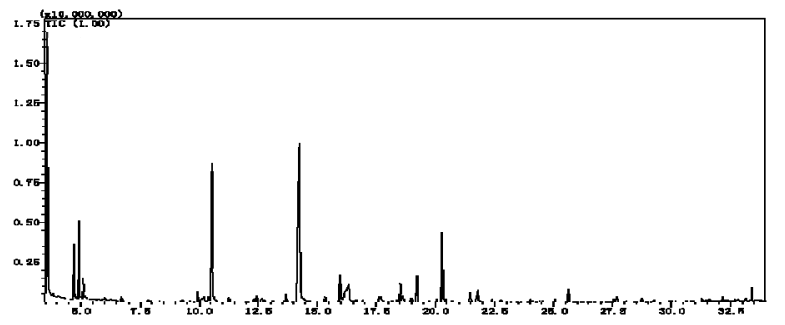

Fig. 1. Total Ion Chromatograms of Aromatic Components in Pineapple Peel Wine.

\subsection{Analysis of esters in pineapple peel wine}

Esters, major volatile components, are an essential part of the aroma skeleton in wines. The volatiles are primarily formed by fruit and alcohol fermentation, contributing to the wine with desirable and fruity sensory properties, including banana, strawberry and green apple $^{[6]}$. As can be seen in table 1, the total relative content of esters in pineapple peel wine was $5.86 \%$. A total of 25 esters represented the largest group, among them 11 fatty acid ethyl esters, 6 higher alcohol acetates, 4 aromatic esters, 3 fatty acid methyl esters and propyl enanthate. Some important esters, suggesting that a more intense fruity aroma could be perceived in such a wine. Ethyl lactate, associated with fruit and cream odors, had the highest content among the various esters, suggesting a rum aroma might be perceived in this wine, followed by phenethyl acetate, contributing to the wine with rich rose aroma and strawberry-like aroma. Moreover, a total of 4 sulfur-containing esters were identified in pineapple peel wine, i.e., methyl 3-methylthiopropionate, ethyl 3methylthiopropionate, 3-(methylthio)propyl acetate and sulfurous acid, 2-ethylhexyl nonyl este, separately.

\subsection{Analysis of Alcohols in pineapple peel wine}

Alcohols, playing a significant role in the fragrance component, are metabolites formed by yeast through sugar catabolism or decarboxylation reaction and deamination of amino acids ${ }^{[7]}$. Such substances, set off the ester aroma and promote the coordination of aromas, have a critict contribution on the aroma of fermented products. Alcohols had the highest concentration of all volatiles in our research, with a total relative content of $62.68 \%$. As shown in table 1, a total of 9 alcohols were detected in this study, namely 3-methyl-1-butano, 2methyl-1-butano, 2,3-Butanediol, 1-pentanol, 3-methyl-, n-heptanol, 1-propanol, 3-(methylthio)-, 1-octanol, phenethyl alcohol and cedrol, respectively. Notably, phenylethyl alcohol had the highest concentration of all volatiles, with a relative content of $32.17 \%$, which constitutes the main aroma substance of pineapple peel wine. It is a derivative of shikimic acid, with a delicate and delicate rose fragrance and rose fragrance. In addition, 3-methylthiopropanol, also known as pinapple alcohol, is found in fruits, beer, white wine, fruit wine and soy sauce. At low concentrations, it can give fruit wine the smell of onion and broth. 1-octanol has fat wax aroma, oily fruit aroma, grass aroma and rose smell.

\subsection{Analysis of fatty acids in pineapple peel wine}

Different concentration of fatty bring about different aroma sensory. Fatty acids was associated with creamy and cheese flavor in low concentration, while the volatiles provide astringent and rancid odors in high concentration, reacting with alcohols to form esters and make the aroma of wine more coordinated. Octanoic acid, having the highest signal intensities of total fatty acids, is usually oily, musty and rancid, but when its concentration is low, it has a pleasant cheese and fruity aroma.

\subsection{Analysis of aldehydes and ketones in pineapple peel wine}

Aldehydes and ketones, formed by alcohol oxidation, are the primary contributors to fruit aromas, providing a fruit flavor with strong fruity, fresh, and green leaves to fruit wines due to their low thresholds ${ }^{[8]}$. However, these compounds are unstable and will be further oxidized to carboxylic acids, reducing their content ${ }^{[9]}$. a total of 5 aldehydes were identified from the current sample, with a total relative content of $0.91 \%$, i.e., nonanal, (e)-2dodecenal, dodecanal, 2-undecenal and n-tetradecanal. Among them, dodecanal was associated with sweet floral and odor, suggesting a citrus aroma might be perceived in this wine. Furaneol, the only one compound belonging to the furans group, was detected from the experimental pineapple peel wine. 


\subsection{Analysis of phenolic compounds in pineapple peel wine}

Phenolic compounds provide the aroma of similar drugs to fruit wine ${ }^{[10]}$. a total of 7 aldehydes were identified in the pineapple pomace fruit wine, with a total relative content of $17.62 \%$. Among them, 2-methoxy-4vinylphenol is the phenolic substance with the highest content in the wine sample. It has a strong spice, clove and fermented aroma, with a smell of fried flowers. Moreover, 4-ethyl-2-methoxyphenol has a sweet and warm spice and herb-like aroma, eugenol has a strong lilac fragrance.

\subsection{Analysis of terpenes in pineapple peel wine}

Terpene compounds generally exist in the fruit in the form of glycosides. During fermentation, they form free and volatile substances under the action of acid or enzymatic hydrolysis, thereby associated with fruity and floral aromas, which are important varieties in fruit wines. The aroma threshold of those group is low, suggesting that it has a greater contribution to the aroma of fruit wine even at a lower concentration ${ }^{[11]}$. The only one compound belonging to the terpene group were identified in this study, i.e., terpineol, responsible for clove aroma. In addition, 4-hexanolide, a lactone, was detected in pineapple peel pomace fruit wine, which has a mild and powerful coumarin-like aroma with a medicinal taste, and a coumarin and caramel-like taste.

Table. 1. The identified volatile compounds of pineapple peel wine using HS-SPME-GC-MS.

\begin{tabular}{|c|c|c|c|}
\hline Peak & $\begin{array}{l}\mathrm{RT} \\
(\min )\end{array}$ & Compound & $\begin{array}{c}\text { Relative } \\
\text { content } \\
/ \%\end{array}$ \\
\hline \multicolumn{4}{|c|}{ Esters } \\
\hline 1 & 4.2 & Isobutyl acetate & 0.03 \\
\hline 2 & 5.1 & Ethyl lactate & 1.55 \\
\hline 3 & 6.7 & \multirow{2}{*}{$\begin{array}{c}\text { Isoamyl acetate } \\
\text { 1-Butanol, 2-methyl-, } \\
\text { acetate }\end{array}$} & 0.25 \\
\hline 4 & 6.8 & & 0.04 \\
\hline 5 & 9.2 & $\begin{array}{c}\text { Benzoic acid, 4-(1,3- } \\
\text { dioxolan-2-yl)-, methyl } \\
\text { ester }\end{array}$ & 0.08 \\
\hline 6 & 9.3 & Ethyl Acetate & 0.09 \\
\hline 7 & 11.3 & $\begin{array}{c}\text { Methyl 3- } \\
\text { methylthiopropionate }\end{array}$ & 0.27 \\
\hline 8 & 12.3 & $\begin{array}{l}\text { Pentanoic acid, 2-hydroxy- } \\
\text { 4-methyl-, ethyl ester }\end{array}$ & 0.12 \\
\hline 9 & 13.2 & $\begin{array}{c}\text { Heptanoic acid, propyl } \\
\text { ester }\end{array}$ & 0.1 \\
\hline 10 & 13.6 & $\begin{array}{l}\text { Butanoic acid, 2-methyl-3- } \\
\text { oxo-, methyl ester }\end{array}$ & 0.02 \\
\hline 11 & 13.7 & $\begin{array}{c}\text { Ethyl 3- } \\
\text { Methylthiopropionate }\end{array}$ & 0.54 \\
\hline 12 & 14.4 & $\begin{array}{l}\text { 3-(Methylthio)propyl } \\
\text { acetate }\end{array}$ & 0.02 \\
\hline 13 & 16.7 & Ethyl octanoate & 0.06 \\
\hline 14 & 18.1 & $\begin{array}{l}\text { Benzeneacetic acid, ethyl } \\
\text { ester }\end{array}$ & 0.06 \\
\hline
\end{tabular}

\begin{tabular}{|c|c|c|c|}
\hline 15 & 18.5 & 2-Phenethyl acetate & 1.34 \\
\hline 16 & 22.4 & Ethyl decanoate & 0.12 \\
\hline 17 & 23.8 & $\begin{array}{c}\text { Carbonic acid, ethyl pentyl } \\
\text { ester }\end{array}$ & 0.05 \\
\hline 18 & 24.1 & Dimethyl phthalate & 0.02 \\
\hline 19 & 27.5 & Ethyl dodecanoate & 0.17 \\
\hline 20 & 30.0 & $\begin{array}{l}\text { Sulfurous acid, 2- } \\
\text { ethylhexyl nonyl ester }\end{array}$ & 0.04 \\
\hline 21 & 30.6 & Ethyl undec-10-enoate & 0.05 \\
\hline 22 & 30.8 & $\begin{array}{l}\text { Ethyl-.beta.-(4-hydroxy-3- } \\
\text { methoxy-phenyl)- } \\
\text { propionate }\end{array}$ & 0.04 \\
\hline 23 & 31.3 & Ethyl tetradecanoate & 0.12 \\
\hline 24 & 32.7 & $\begin{array}{l}\text { Tridecanoic acid, 12- } \\
\text { methyl-, methyl ester }\end{array}$ & 0.07 \\
\hline 25 & 33.4 & $\begin{array}{c}\text { Ethyl palmitate } \\
\text { Alcohols }\end{array}$ & 0.61 \\
\hline 26 & 3.5 & 3-methyl-1-butano & 6.91 \\
\hline 27 & 3.6 & 2-methyl-1-butano & 4.75 \\
\hline 28 & 4.7 & 2,3-Butanediol & 8.35 \\
\hline 29 & 5.9 & 1-Pentanol, 3-methyl- & 0.05 \\
\hline 30 & 9.6 & n-Heptanol & 0.03 \\
\hline 31 & 9.9 & 1-Propanol, 3-(methylthio)- & 0.78 \\
\hline 32 & 12.8 & 1-Octanol & 0.12 \\
\hline 33 & 14.2 & Phenethyl alcohol & 22.18 \\
\hline 34 & 28.1 & $\begin{array}{l}\text { Cedrol } \\
\text { Acids }\end{array}$ & 0.04 \\
\hline 35 & 6.0 & Butanoic acid, 3-methyl- & 0.18 \\
\hline 36 & 6.3 & Butanoic acid, 2-methyl- & 0.08 \\
\hline 37 & 8.0 & Butanoic acid, 4-hydroxy- & 0.05 \\
\hline 38 & 10.2 & Hexanoic acid & 0.68 \\
\hline 39 & 16.3 & Octanoic Acid & 4.29 \\
\hline 40 & 18.4 & $\begin{array}{c}\text { Pentanoic acid, 2-methyl-4- } \\
\text { oxo- }\end{array}$ & 0.13 \\
\hline 41 & 19.0 & Nonanoic acid & 0.31 \\
\hline 42 & 21.8 & $\begin{array}{l}\text { n-Decanoic acid } \\
\text { Phenols }\end{array}$ & 1.28 \\
\hline 43 & 16.0 & Phenol, 4-ethyl- & 2.15 \\
\hline 44 & 18.6 & Phenol, 4-(2-propenyl)- & 0.62 \\
\hline 45 & 19.2 & 4-ethyl guaiacol & 1.98 \\
\hline 46 & 20.3 & 2-Methoxy-4-vinylphenol & 5.66 \\
\hline 47 & 21.5 & Eugenol & 0.64 \\
\hline 48 & 24.0 & $\begin{array}{l}\text { (E)-Phenol, 2-methoxy-5- } \\
\text { (1-propenyl)- }\end{array}$ & 0.21 \\
\hline 49 & 25.6 & $\begin{array}{c}\text { Phenol, 2,4-bis(1,1- } \\
\text { dimethylethyl)- } \\
\text { Aldehydes }\end{array}$ & 0.89 \\
\hline 50 & 13.8 & Nonanal & 0.05 \\
\hline 51 & 21.6 & (E)-2-Dodecenal & 0.07 \\
\hline 52 & 22.8 & Dodecanal & 0.09 \\
\hline 53 & 24.6 & 2-Undecenal & 0.07 \\
\hline 54 & 31.6 & n-Tetradecanal & 0.03 \\
\hline 55 & 12.7 & $\begin{array}{l}\text { Furaneol } \\
\text { Terpenes }\end{array}$ & 0.32 \\
\hline 56 & 16.6 & $\begin{array}{l}\text { Terpineol } \\
\text { Others }\end{array}$ & 0.07 \\
\hline 57 & 12.2 & 4-hexanolide & 0.02 \\
\hline
\end{tabular}




\section{Conclusion}

In this study, we investigated the volatile profile of pineapple peel wine by HS-SPME-GC/MS. Results obtained showed that there were abundant volatile components in the wine samples. A total of 57 volatiles were identified, including 25 esters, 9 alcohols, 8 acids, 7 phenolic compounds, 6 aldehydes and ketones, 1 terpene and 1 lactone, respectively. Among various aroma substances, the types of esters are the most, while the content of alcohols is the largest. Within these, phenethyl alcohol, 3-methyl-1-butano, 2-methyl-1butano, 2,3-Butanediol and 2-Methoxy-4-vinylphenol were the major constituents. The work might help comprehensive insight into the flavor characteristics of pineapple peel wine and provide potential application of pineapple peel.

\section{Acknowledgments}

This work was financially supported by the Hainan Provincial Natural Science Foundation of China (219QN295, 219QN294), the Science and Technology Projects of Zhanjiang (2018A01015), and the Central Public-interest Scientific Institution Basal Research Fund for Chinese Academy of Tropical Agricultural Sciences (1630122017013, 1630122020002).

\section{References}

1. S. Chakraborty, P.S. Rao, H.N. Mishra. Innov. Food Sci. Emerg. 28:10-21 (2015).

2. A. Choonut, M. Saejong, K. Sangkharak. Energy Procedia, 52: 242-249 (2014).

3. M.P. Riya, K.A. Antu, T. Vinu, et al. J. Sci. Food Agr. 94: 943-950 (2014).

4. A. Freitas, M. Mold ao-Martins, H.S. Costa, et al. J. Sci. Food Agr. 95: 44-52 (2015).

5. Z. Xiang, X. Chen, Z. Zhao, et al. J. Sep. Sci. 41(23): 4315-4322 (2018).

6. E. Sánchez-Palomo, J.A. Delgado, M.A. Ferrer, et al. Food Res. Int. 119: 135-142 (2019).

7. S.J. Zhang, A.P. Mikael, J. Liu, et al. Molecules 20(12): 21609-25 (2015).

8. M.K. Lina, A. Daus, R. Porat. Int. J. Food Sci. Tech. 48(8): 1569-1578 (2013).

9. V.I. Petropulos, E. Bogeva, T. Stafilov, et al. Food Chem. 165(3): 506-514 (2014).

10. M.M. Losada, J, ANDRÉS, J. Cacho, et al. Food Chem. 125(3): 884-891 (2011).

11. J. Cai, B.Q. Zhu, Y.H. Wang, et al. Food Chem. 154(2): 217-229 (2014). 